\title{
ISOLATION AND CHARACTERIZATION OF OLEAGINOUS MARINE YEAST PRODUCING OF FATTY ACIDS
}

\author{
Abd-Elmoez A. Zarea ${ }^{* 1}$, Said E. Desouky ${ }^{1}$, Gadallah M. Abu-Elreesh ${ }^{2}$, Mohammed G. \\ Barghoth $^{1}$, Mohamed roushdy ${ }^{1}$ \\ ${ }^{1}$ Department of Botany and Microbiology, Faculty of Science, Al-Azhar University, 11884 \\ Nasr, Cairo, Egypt. \\ ${ }^{2}$ Engineering and Biotechnology Research Institute (GEBRI), City of Scientific Research \\ and Technological Applications (SRTA-City), New Borg Al-Arab City, Alexandria 21934, \\ Egypt. \\ *corresponding author: abd-elmoez@azhar.edu.eg
}

\begin{abstract}
:
Because of the limitation of lipid sources from animal and plant, there are great interest searches to finding new alternative lipid sources such as microbial cells that can be used as a key player in different applications such as biodiesel production as well as pharmaceutical and food industries. Therefore, ten sediment and seawater samples were collected from different marine environments for oleaginous yeast isolation purposes. A total of 20 yeast isolates were obtained and screened to accumulate intracellular fatty acids using Nile red staining under a fluorescence microscope as well as Triphenyltetrazolium chloride (TTC) dye at $\mathrm{A}_{485 \mathrm{~nm}}$. Amongst all isolates, two yeast isolates namely $\mathrm{C} 5$, and L4 have exhibited the best results for cellular lipid content accumulation. They showed the highest potentiality of lipid accumulation from 14.3 to $15.1 \mathrm{gl}^{-1}$, respectively of dry mass and the percent of lipid content appeared from 25.4 to $28.2 \%$, respectively when cultured on YPD medium at $25^{\circ} \mathrm{C}$. Based on phenotypic and genotypic criteria these isolates were identified as Candida parapsilosis $\mathrm{C} 5$ and Cryptococcus albidus L4. The study of fatty acids profile composition of these isolates showed that linoleic acid (C18:2), gamaLinolenic acid (C18), oleic acid (C18:1), stearic acid (C18:0), and palmitic acid (C16:0) are the main fatty acids produced that similar to those present in plant oils. The main fatty acids obtained by both strains represent $\simeq 76 \%$ and $91 \%$ for isolate C5 and L4, respectively. Also, these strains displayed $68-70 \%$ of unsaturated fatty acids and produced an appropriate amount of saturated fatty acids ranged between 30.5 to $32 \%$ of the total fatty acids make these strains a suitable solution to solve many global problems related to dietary supplements, diseases treatment, and energy renewable sources such as biodiesel production.
\end{abstract}

Keywords: Isolation, marine, oleaginous, yeast, polyunsaturated fatty acids (PUFAs), Lipid production, screening, Candida parapsilosis, Cryptococcus albidus. 


\section{1-Introduction}

Polyunsaturated fatty acids (PUFAs ) are essential components of phospholipid cell membranes, regulating the fluidity of cellular membranes and modulating enzyme activities, carriers, and membrane receptors as well as it may be useful in the prevention and management of many chronic diseases such as problems resulted from auto-immune disorders, cancer, hypertension, diabetes, inflammatory and coronary heart disease, atopic eczema, major depression, schizophrenia, Alzheimer dementia and multiple sclerosis (Yeung et al., 2018; Wang et al., 2019).

Fish is the most important dietary source of PUFAs for humans, as well as a good source of vitamins, proteins, and minerals. The recommended regular PUFAs intake levels differ across the world, depending on the regional type or health organizations recommendations. Nonetheless, most experts believe that the average person can eat at least two portions of fish every week one of them preferred to be oily (Mohanty et al., 2019).

Therefore, as the world's population and demand for seafood grow, and wild catch fisheries exceed over their exploitable limits, because more fish bound for the table market is being farmed. During the past few decades, aquaculture has been the fastest-growing, animal-food-producing industry, outpacing population growth, and now provides roughly half of the world's fish and seafood for human requirements (Sprague et al., 2016).

The growing demand for fish oil from aquaculture to pharmaceutical industries, and other manufactures requirements as well as the permanent natural climate changes, affect oil supply and prices. Also, overfishing has depleted ocean fisheries, making them a nonrenewable source of PUFAs to meet rising demand (Harwood, 2019). Furthermore, environmental pollutants have been discovered in fish oils, necessitating the creation of a renewable, land-based source of PUFAs. To overcome these constraints, biotechnological industries began producing PUFAs directly from microorganism's mainly oleaginous microorganisms in large-scale fermentation processes (Kraic et al., 2018).

Oleaginous microorganisms including yeast, filamentous fungi, microalgae, bacteria, and cyanobacteria, have the potential ability to accumulate intracellular lipids up to $20 \%$ of their dry mass and hence they are considered desirable next-generation precursors for fatty acids or lipids production (Bruder et al., 2018).

Oleaginous bacteria have received less attention to date because their lipid content is lower than that of other oleaginous microorganisms, and their growth rates are also slower. Oleaginous cyanobacteria and microalgae are desirable hosts for the development and production of fatty acids due to their special photosynthesis capability, which transforms solar energy and $\mathrm{CO}_{2}$ directly into cellular lipid contents (Nilsson et al., 2020). However, they are also more difficult to manipulate genetically than bacteria, yeast, and fungi, and their cultivation and growth processes are more complicated and costly. These previous obstacles have limited their use in the production of fatty acid-derived chemicals 
via metabolic engineering. Similarly, the use of oleaginous filamentous fungi as production candidate hosts is hampered by a lack of effective genetic transformation techniques (Kumar et al., 2019).

In contrast to other oleaginous microbial lipid sources, oleaginous yeast has several advantages that make it the most promising cell factory for producing fatty acid-derived chemicals. They can achieve extremely high levels of lipid accumulation of more than $70 \%$ of their dry weight in easy and inexpensive culture. They can also use various types of waste residues as substrate nutrients and they are more genetically tractable than other oleaginous microorganisms. Moreover marine yeasts have several distinct and promising advantages over terrestrial yeasts, including greater osmosis tolerance, increased special chemical productivity, and the production of industrial enzymes make them a great deal of potential for use in a variety of industries (Diwan \& Gupta, 2020). Therefore, this study aimed to isolate, identify, and screen for oleaginous marine yeast strains with high specific growth rates and high cellular lipid content that could be used as the precursor of PUFA production as well as study the characterization of fatty acid profiles obtained by these strains.

\section{Materials and Methods}

\subsection{Samples collection}

Ten sediment and seawater samples were collected from the Abu Qir Bay in the Mediterranean Sea at Alexandria governorate (March 2017) and the Red Sea (Suez Canal, January 2017) in Egypt. The collected samples were stored in icebox at $4{ }^{\circ} \mathrm{C}$ and transferred under aseptic conditions to the laboratory for yeast isolation procedures.

\subsection{Isolation and cultivation of lipid producing yeast}

The isolation and cultivation procedure were performed within 24 hours of samples collection according to the method described by Krieg \& Padgett (2011).

\subsection{Screening for lipid production by yeast isolates}

The ability of purified yeast colonies to produce polyunsaturated fatty acids was screened by using two different methods. Firstly, according to (Kimura et al., 2004) protocol by measuring the fluorescence of Nile Red (9-diethylamino-5Hbenzo $[\alpha]$ phenoxazine-5-one) staining under a fluorescence microscope (BX-40, Olympus, Tokyo, Japan) and the isolates that showed the higher light intensity was selected as lipid producing strain. The previously selected isolates were further screened for their internal lipid contents by measuring the absorbance of Triphenyltetrazolium chloride (TTC) at wavelength $485 \mathrm{~nm}$ using of $0.6 \%$ TTC solution prepared according to the method suggested by (Arora et $\boldsymbol{a l . , 2 0 1 5}$ ) and the staining procedures were conducted based on the method reported by (Vadivelan \& Venkateswaran 2014) using of methanol replaced of 
ethyl acetate. Yeast isolates with the higher potential of lipid accumulation were maintained in YPD agar slants to use for further characterization and identification.

\subsection{Identification of the most promising lipid-producing isolates}

\subsubsection{Morphological and biochemical characteristics}

Morphological properties of the most promising lipid-producing yeast isolates were investigated after incubation at $25^{\circ} \mathrm{C} \pm 1$ for $48 \mathrm{~h}$ on YPD agar plates. The purity and cell shape of yeast isolates were examined by methylene blue stain $(0.1 \%$, w/v) under an oil immersion lens (100X).

The ability of these isolates to grow aerobically after incubation for $48 \mathrm{~h}$ on different carbon sources such as citrate, glycerol, sucrose, D-glucose, xylitol, lactose, soluble starch, arabinose, and D-xylose and different nitrogen sources such as nitrate, ammonium sulfate, and urea as the sole sources of carbon and nitrogen was investigated using replica plate method and compared with a negative control without carbon and nitrogen. Also, the abilities of these isolates to grow at different temperatures ranged from 4 to $40^{\circ} \mathrm{C}$ were determined (Mbagwu, 2017).

\subsubsection{Genetic characteristics}

Genetic identification of the most efficient lipid-producing strains was accomplished by using $18 \mathrm{~S}$ ribosomal RNA. Genomic DNA of the most potent strains was extracted by the CTAB method and amplified according to (Van Dijken et al., 2000) with primers ITS5 (5'- GACTCCTTGGTCCGTGTT -3') as forward and ITS4 (5' ATTACCGCGGCTGCTGGCACC- 3') as the reverse. The products of polymerase chain reaction $(\mathrm{PCR})$ were tested by gel electrophoresis containing $1 \%$ of agarose and $0.1 \mu \mathrm{g} / \mathrm{ml}$ of ethidium bromide dye and carried out at 125 volts. Then, the amplified product was purified using EZ-10 Spin Column PCR Products Purification Kit BS664 (Bio-basic, USA). The sequencing was performed by Applied Bio-systems automated DNA sequencer-Sanger Sequencing Technology (model; ABI 3730XL DNA Analyzer-Applied Bio-systems, USA; service provided by Macrogen Inc., South Korea). The alignments and sequence analyses were performed by the BLAST database of the National Center for Biotechnology Information (NCBI-BLAST programs) and the phylogenetic relationship of studied strains was analyzed and displayed based on distance-based Neighbor-Joining tree. 


\subsection{Poly-unsaturated fatty acids Production conditions}

\subsubsection{Preparation of inoculum}

The propagation process for the most potent strains was carried out in YPD broth medium and incubated at $25{ }^{\circ} \mathrm{C} \pm 1{ }^{\circ} \mathrm{C}$ for $48 \mathrm{~h}$ under shaking conditions (150 rpm). The optical density (OD) of the cultures was adjusted at $1 \mathrm{~nm}$. Two milliliters of cultured broth medium were centrifuged for $5 \mathrm{~min}$ at $8000 \mathrm{xg}$, and washed with sodium chloride saline solution $(0.9 \%)$, and centrifuged again and finally the collected pellets of lipid producing strain re-suspended in one milliliter of saline solution and used as standard inoculum (Yuangsaard et al., 2013).

\subsubsection{Production medium}

Cellular lipid accumulation by the most promising oleaginous yeast isolates (C5 and L4) was observed on the productive medium through the cultivation of one milliliter of propagation culture on a nitrogen-limited medium composed of $(\mathrm{g} / \mathrm{L}): 50$ glucose, 5 peptone, and 3 yeast extract dissolved in one liter of seawater and the $\mathrm{pH}$ was adjusted at 5.8 and incubated at $25^{\circ} \mathrm{C} \pm 2$ under shaking condition (150 rpm) (Pan et al., 2009).

\subsubsection{Biomass determination by cell dry weight}

Biomass dry weight (CDW, $\left.\mathrm{gL}^{-1}\right)$ of most potent strains was evaluated gravimetrically according to (Chang et al., 2015). Biomass of cultured cells was collected by centrifuging at 5,000 $\mathrm{xg}$ for $15 \mathrm{~min}$, washed twice with the same volume sterile saline solution, and then dried at $55^{\circ} \mathrm{C}$ to the constant weight of cell biomass. Triplicate samples were determined for dry biomass and total lipid content.

\subsection{Lipid extraction and purification}

Cellular lipid content of yeast isolates was extracted based on the standard methodology described by (Bligh \& Dyer 1959) in which $50 \mathrm{ml}$ of cultured cells was centrifuged at $5000 \mathrm{xg}$ for $5 \mathrm{~min}$, and the pellets were rinsed twice with $50 \mathrm{ml}$ of distilled water and followed by addition into $10 \mathrm{ml}$ of $4 \mathrm{M} \mathrm{HCl}$ and incubated for two hours at $60^{\circ} \mathrm{C}$ to lysis the cell wall of yeast strains. The above acid-hydrolyzed solution was constantly stirred at room temperature with $20 \mathrm{ml}$ of solvents (chloroform/methanol mixture, 2:1; v:v) for $3 \mathrm{~h}$. after that, the solution was centrifuged at $2000 \mathrm{xg}$ for $5 \mathrm{~min}$ at room temperature to separate the organic lower phases from an aqueous upper phase. The organic lower phase containing the lipids content was filtered through filter paper and recovered then completely evaporated by oven at $55{ }^{\circ} \mathrm{C}$ until constant weight and dry biomass, and then the lipid content was determined gravimetrically as previously mentioned. 


\subsection{Fatty acid composition and GC-MS analysis}

The fatty acids of cellular lipid content were subjected to the methanolysis process according to (Amaretti $\boldsymbol{e t}$ al., 2010) as methyl esters by mixing crude lipid extract with 2 $\mathrm{ml}$ of methanolic sulfuric acid $\left(6 \% \mathrm{H}_{2} \mathrm{SO}_{4}\right)$ for $30 \mathrm{sec}$. After that, two milliliters of petroleum ether and 1 milliliter of distilled water were mixed to collected fatty acid methyl esters (FAMEs) for $30 \mathrm{sec}$ and the upper petroleum layer was evaporated at $38^{\circ} \mathrm{C}$ under nitrogen atmosphere until reached to dryness state. The residual of FAMEs were redissolved in $200 \mathrm{ml}$ hexane and analyzed by Gas Chromatography (6890N) connected by Agilent 55973 Mass Spectrometer with an HP-5 capillary column $(30 \mathrm{mx} 0.25 \mathrm{~mm}$ id, 0.25 $\mathrm{mm}$ film thickness; J\&W Scientific, USA). The injection temperature was maintained at $300{ }^{\circ} \mathrm{C}$ and the oven was programed for $2 \mathrm{~min}$ at $150{ }^{\circ} \mathrm{C}$, then increased to $300{ }^{\circ} \mathrm{C}$ at $4{ }^{\circ} \mathrm{C}$ $\min ^{-1}$ and maintained for $20 \mathrm{~min}$ at this temperature and the carrier gas was helium at a flow rate of $1.0 \mathrm{ml} \mathrm{min}{ }^{-1}$. The Fatty acid methyl esters were quantified and identified by comparing their retention time and mass spectra with the spectral standard of Wiley and NIST (Rubiolo et al., 2010).

\section{Results and Discussion}

\subsection{Isolation and Screening of oleaginous yeast}

A total of 20 yeast isolates were obtained from different marine samples collected from two harbors from the Mediterranean Sea and the Red Sea in Egypt. These isolates exhibited the typical morphology and properties of the yeast cell.

Yeasts are a polyphyletic group of basidiomycetous like Cryptococcus laurentii and ascomycetous such as Pichia kudriavzevii (Barghoth et al., 2018) fungi with the ability to grow in unicellular manner. Yeasts are isolated from a wide range of aquatic, marine, atmospheric and terrestrial habitats. Yeasts seldom occur in the absence of either molds or bacteria. Consequently, selective techniques are often used for recovery of yeasts, employing media that permit the yeasts to grow, while suppressing the growth of molds and bacteria (Klymiuk, 2018).

Preliminary screening for cellular lipid accumulation potential of the collected yeast isolates was point out by Nile red stain based on the ability of these isolates to emit the yellow gold fluorescence due to their cellular lipid content. Amongst all isolates, only two yeast strains coded as C5 and L4 revealed a significant content of cellular lipid with lipid accumulation ranged from 25 to higher than $35 \%$ of the cell area when stained with the Nile red (Fig. 1). Nile red is one of the faster separation techniques that prefer by many researchers to select oil-producing strains from other non-producing ones through the emitting of gold-like fluorescence when reacting with a hydrophobic compound such as lipids (Govender $\boldsymbol{e t}$ al., 2012). The internal lipid concentration inside yeast strains is directly correlated with the fluorescence intensity of cells under UV light in which the 
stronger fluorescence intensity the higher accumulation of cellular lipid contents (Daniel $\boldsymbol{e t}$ al., 2011).

The appearance of different lipid body shapes in oleaginous yeast when stained with Nile red dye was fully consistent with the results previously described by many authors depending on the genus even to species and the culture growth conditions. Moreover, the fluorescence emission observed in Fig. 1 was completely identical to those present in other oleaginous yeasts (Kimura et al., 2004; Kraisintu et al., 2010; Enshaeieh et al., 2014; Vinarta et al., 2016).

The potential ability of isolates C5 and L4 to accumulate lipid droplets was confirmed calorimetrically by measuring the reduction of TTC stain from colorless to pink/red color at $485 \mathrm{~nm}$. The data recorded in Table 1 demonstrated that the higher degree of staining at $\mathrm{A}_{485 \mathrm{~nm}}$ was exhibited by isolate $\mathrm{L} 4$ (O.D. $\simeq 2.51$ ) followed by isolate C5 (O.D. $\simeq 1.32$ ).

The reduction of TTC dye (colorless) to triphenylformazan (TPF) (pink/red color) indicates that the capabilities of these isolates to form of PUFAs because of the reduction of TTC dye is regulated by numerous enzymes (dehydrogenases) responsible for the PUFAs biosynthesis process (Ryan et al., 2010; Abd El Razak et al., 2014; Xue et al., 2018). The potential ability of lipid accumulation inside yeast strains has been noted by many investigators (Meng et al., 2009; Zhu et al., 2012; Magdouli et al., 2014 ; Ochsenreither et al., 2016; Kosa et al., 2017; Osorio-Gonzalez et al., 2019; Maza et al., 2020; Marika et al., 2021).

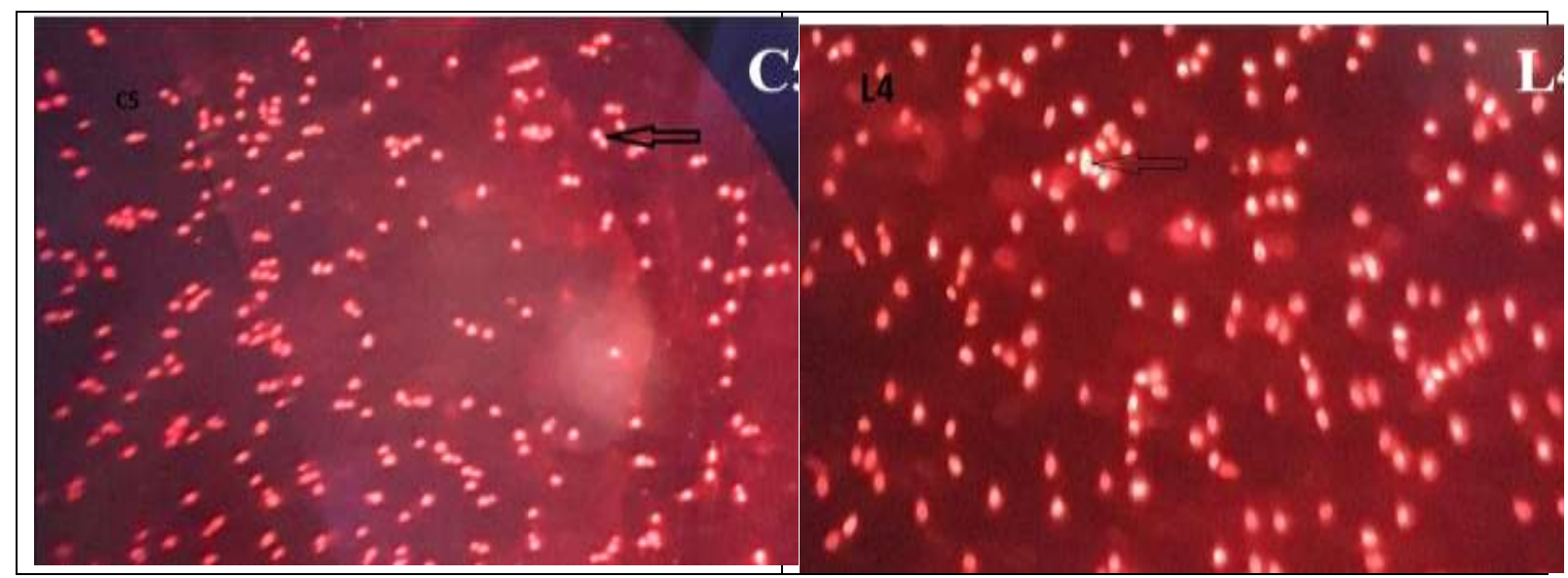

Fig. 1: Fluorescence micrographs of lipid droplets of isolates C5 and L4 stained with the Nile Red dye. 


\subsection{Lipid content and biomass determination}

The quantitative assessment of dry biomass and lipid content for the most promising yeast isolates C5 and L4 after growing on YPD medium containing a high amount of glucose sugar and limited source of nitrogen at $25^{\circ} \mathrm{C}$ and 5.8 of $\mathrm{pH}$ represented in Table 1. The most potent strains C5 and L4 showed the highest potentiality of lipid accumulation from 14.3 to $15.1 \mathrm{gl}^{-1}$, respectively of dry mass and the percent of lipid content appeared from 25.4 to $28.2 \%$ respectively (Ageitos et al. 2011) reported that microorganisms that accumulate lipid content more than $20 \%$ corresponding to their dry mass are known as oleaginous microorganisms therefore isolates $\mathrm{C} 5$ and L4 indeed oleaginous yeast because they produce lipid content between 25.4 to $28.2 \%$.

In general, many previous studies reported that oleaginous yeasts can accumulate and store cellular lipids when the cultivation nutrients become exhausted except the source of carbon is still available and hence they assimilating this carbon in the shape of lipids droplets inside their cells (Ratledge \& Wynn, 2002; Czabany et al., 2007; Vinarta et al., 2016).

Biomass production by these strains $\left(14.3-15.1 \mathrm{gl}^{-1}\right)$ is too similar to results reported by other oleaginous yeasts such as Cryptococcus curvatus NRRLY1511, Rhodosporidium glacialis, Candida freyschussii, and Rhodosporidium toruloides Y4, and some Antarctic Rhodotorula spp. (Li et al., 2007; Li et al., 2008; El-Fadaly et al., 2009; Amaretti et al., 2012; Vinarta et al., 2016). Also, the lipid bodies that accumulate in oleaginous yeast have different percent, composition and shapes depending on the genus even to species producers and culture conditions such as carbon and nitrogen sources, nutrient availability, incubation time and temperature, inoculum size, $\mathrm{pH}$ of medium (Kraisintu et al., 2010; Ravikumar et al., 2012).

The ability of oleaginous yeasts such as genera Cryptococcus, Lipomyces, Rhodotorula, Yarrowia, and Trichosporon to accumulate a high percentage of lipid content inside their cells has reported by many investigators (Kurtzman et al., 2011; Vinarta et al., 2016; Park et al., 2017; Maza et al., 2020).

Table 1: Staining degree, dry biomass, and total lipid content of yeast isolates $\mathrm{C5}$ and L4

\begin{tabular}{|c|c|c|c|}
\hline Isolates & $\begin{array}{l}\text { degree of Staining }\left(\mathrm{A}_{485}\right. \\
\mathrm{nm})\end{array}$ & $\begin{array}{l}\text { Dry biomass } \\
(\mathrm{g} / \mathrm{L})\end{array}$ & $\begin{array}{l}\text { Total lipid content } \\
(\%)^{-}\end{array}$ \\
\hline C5 & 1.32 & 14.3 & 25.4 \\
\hline L4 & 2.51 & 15.1 & 28.2 \\
\hline
\end{tabular}




\subsection{Identification of oleaginous yeast strains}

Morphological and microscopical characteristics of the most potent isolates showed that the isolate C5 appear cream white color, faint to shiny and oval to spherical shape with bipolar budding. While the isolate L4 appear mucoid or slimy with yellowish-white color and elongated to oval shape their cells surrounding with sticky layers. Table 2 showed the biochemical and physiological characterizations of isolates C5 and L4 in which both strains can utilize D-glucose, glycerol, starch, xylitol, D-xylose, arabinose, citrate, and sucrose as the sole source of carbon but the isolate L4 not able to consume lactose sugar. In addition to these isolates can utilize all nitrogen sources except the isolate C5 not able to use organic nitrogen (urea). The lower temperature degree affects the growth of isolate C5 while the higher temperature degree inhibited the growth of isolates L4.

Table 2: Biochemical properties of the oleaginous yeast isolates $\mathrm{C} 5$ and $\mathrm{L} 4$.

\begin{tabular}{ccc}
\hline Test & Isolate C5 & Isolate L4 \\
\hline Glycerol & $+\mathrm{ve}$ & $+\mathrm{ve}$ \\
Starch & $+\mathrm{ve}$ & $+\mathrm{ve}$ \\
D-Glucose & $+\mathrm{ve}$ & $+\mathrm{ve}$ \\
Lactose & $-\mathrm{ve}$ & $+\mathrm{ve}$ \\
Xylitol & $+\mathrm{ve}$ & $+\mathrm{ve}$ \\
Sucrose & $+\mathrm{ve}$ & $+\mathrm{ve}$ \\
L-Arabinose & $+\mathrm{ve}$ & $+\mathrm{ve}$ \\
D-Xylose & $+\mathrm{ve}$ & $+\mathrm{ve}$ \\
Citrate (Sodium) & $+\mathrm{ve}$ & $+\mathrm{ve}$ \\
Urea & $-\mathrm{ve}$ & $+\mathrm{ve}$ \\
Nitrate & $+\mathrm{ve}$ & $+\mathrm{ve}$ \\
Ammonium Sulfate & $+\mathrm{ve}$ & $+\mathrm{ve}$ \\
Growth At $4{ }^{\circ} \mathrm{C}$ & $-\mathrm{ve}$ & $+\mathrm{ve}$ \\
Growth At $25^{\circ} \mathrm{C}$ & $+\mathrm{ve}$ & $+\mathrm{ve}$ \\
Growth At $37^{\circ} \mathrm{C}$ & $+\mathrm{ve}$ & $-\mathrm{ve}$ \\
Growth At $40^{\circ} \mathrm{C}$ & $+\mathrm{ve}$ &
\end{tabular}

The selected isolates C5 and L4 that appeared the highest potential capability in lipid production were identified using the genetic taxonomic approach. The result of BLAST analysis of the 18S rRNA gene sequence of the most potent yeast strains C5 and L4 were showed the perfect match of strain C5 with Candida parapsilosis strain CBS 604 (Gen-bank access number; MH545914.1), Candida metapsilosis strain CBS 10907 (MK394127.1) and Candida parapsilosis isolate XS2 (KY118177.1) with similarity of 97.6\% for all these strains with more accession identical to Candida parapsilosis species and hence it is identified as Candida parapsilosis C5 (Fig. 2). On the other hand, the evolutionary distance of strain L4 with closely related species revealed a good match with Cryptococcus albidus also known as Naganishia albida (AB032617.1) and Basidiomycete 
yeast sp. BG02-5-23-001-C2 (AY520208.1) with a similarity of $91.98 \%$ and $91.88 \%$, respectively and hence it is identified as Cryptococcus albidus L4 (Fig. 3).

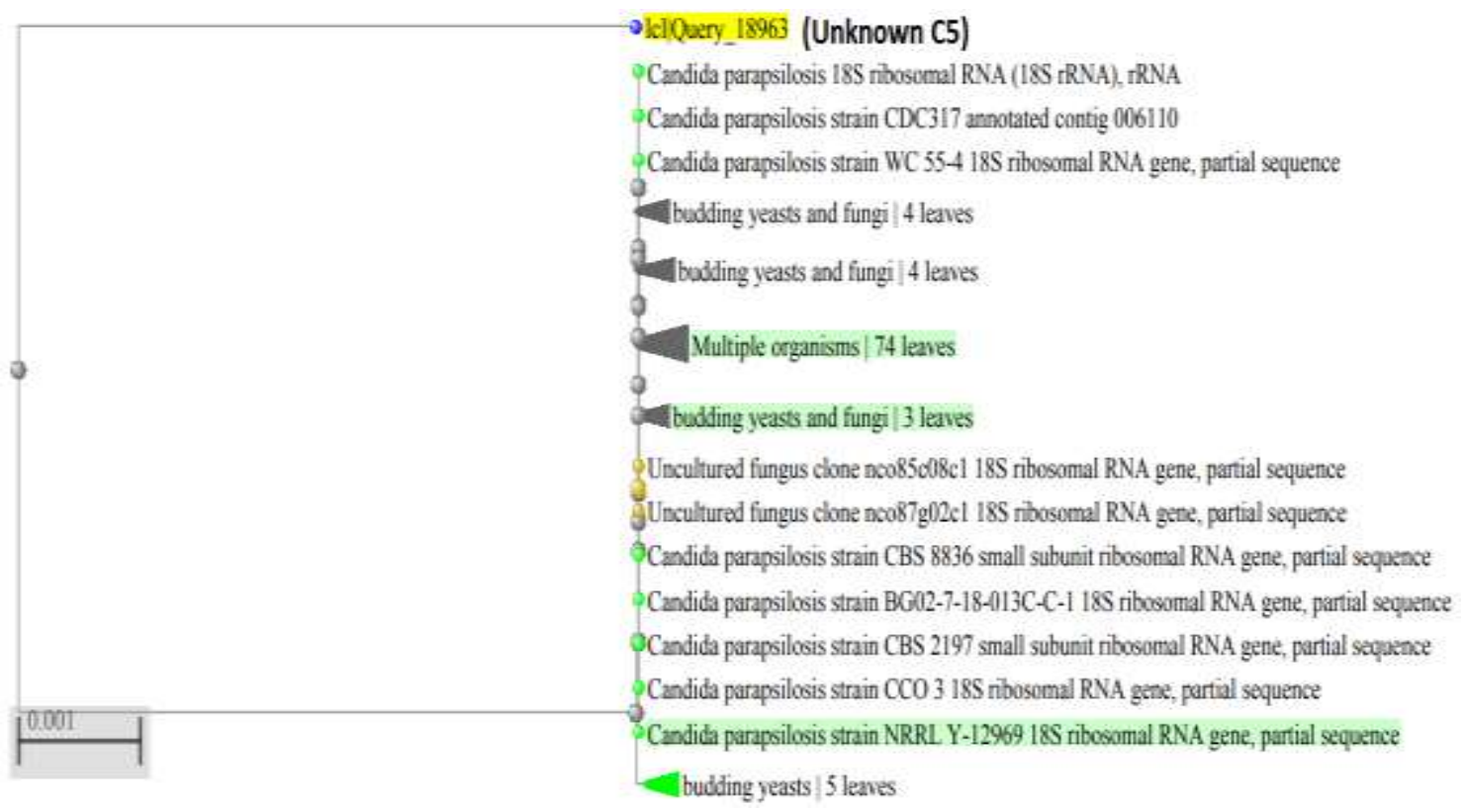

Fig. 2. Phylogenetic tree based on the sequence of $18 S$ rRNA gene showing the similarity of oleaginous yeast isolate $\mathrm{C5}$ with closely related strains.

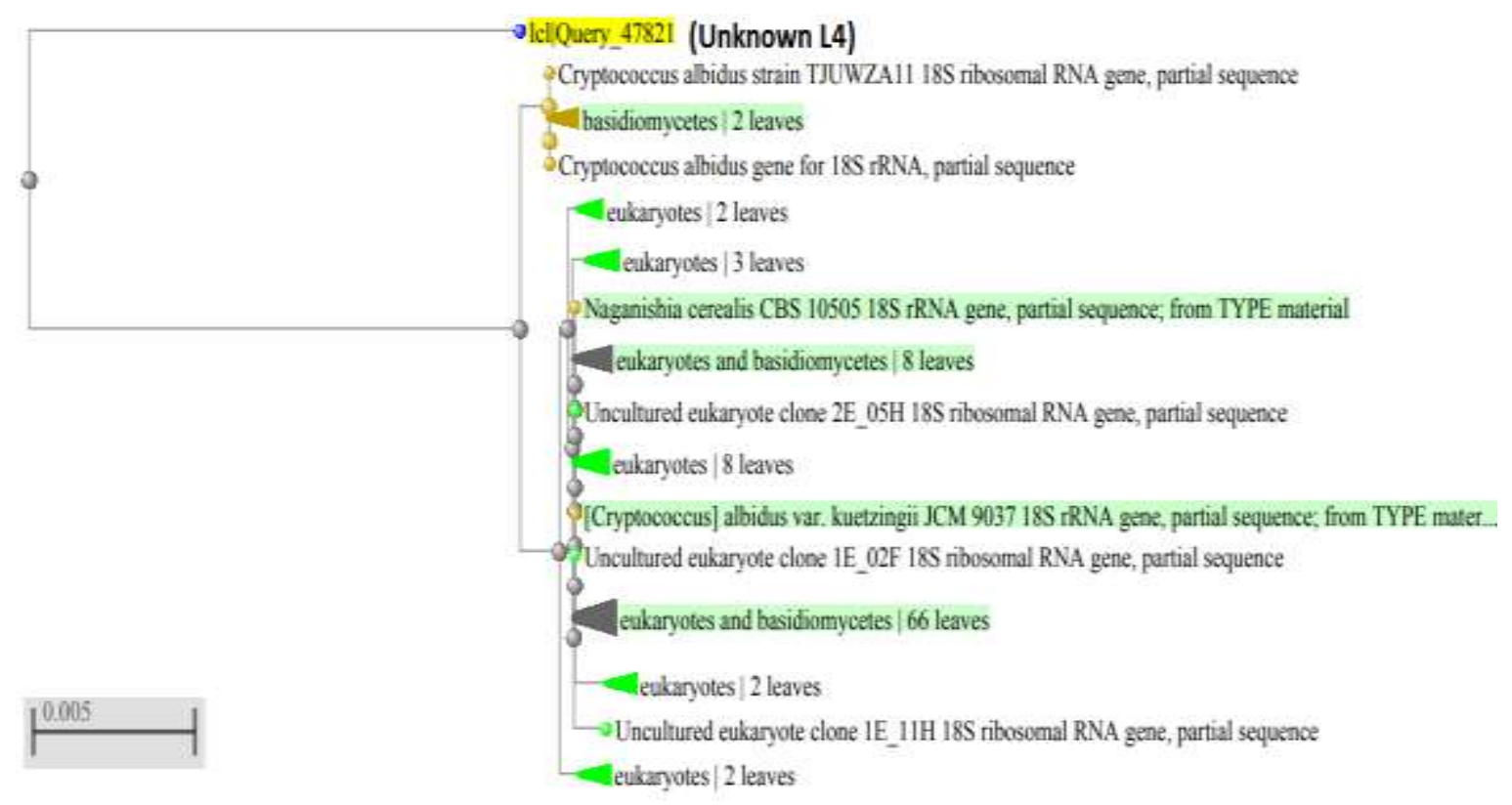

Fig. 3. Phylogenetic tree based on the sequence of $18 S$ rRNA gene showing the similarity of oleaginous yeast isolate $\mathrm{L} 4$ with closely related strains. 


\subsection{Fatty acid composition and profile analysis}

In this study, the most promising yeast isolates Candida parapsilosis C5 and Cryptococcus albidus L4 which showed the highest efficiency to accumulate cellular lipid droplets were subjected to detect their fatty acid profile composition. Determination of the fatty acid profile of oils produced by yeast isolates is highly essential because its composition affects the biotechnological application routes such as biodiesel quality or dietary supplements or disease treatment (Maza et al., 2020).

Table 3 shows that the composition of the fatty acid profile including saturated, polyunsaturated, monounsaturated, and total lipid content accumulating by strains Candida parapsilosis C5 and Cryptococcus albidus L4. Data observed in this work point out that these strain produced a mixture of fatty acids similar to those present in vegetable oils such as triacylglycerols (TAG), linoleic acid (C18:2), oleic acid (C18:1), stearic acid (C18:0), and palmitic acid (C16:0) (Figs 4, 5). Many investigators reported that oleaginous yeasts have the potential ability to produce microbial oils with a composition similar to vegetable or plant oils and containing predominantly monounsaturated fatty acid (MUFA) or saturated fatty acid (SFA) with a carbon chain length of 16 and 18 (Li et al., 2008; Beopoulos et al., 2009; Meng et al., 2009; Papanikolaou \& Aggelis, 2011; Dalia et al., 2014; Kosa et al., 2018; Maza et al., 2020).

Linoleic acid (LA) is commonly produced from plants; in particular, it was enriching presented in seed oils. Linoleic acid is the only essential omega- 6 fatty acid that must be obtained from the daily diet. Many other omega-6s fatty acids can be created from linoleic acid using elongase and desaturase enzymes and therefore linoleic acid serves as a precursor for the production of the essential fatty acid such as arachidonic acid, as well as other n-6 acyl species (Visioli \& Poli, 2020).

On the same side, oleic acid is the most common unsaturated fatty acid that can be used as the precursor for the production of most other PUFAs. For instance plants produce both n-3 and n-6 PUFAs from oleic acid while animals can be elongate and de-saturate oleic acid into a variety of n-9 fatty acids (Saini \& Keum, 2018) 
Table 3: Fatty acid methyl ester profiles of strains Candida parapsilosis C5 and Cryptococcus albidus $\mathbf{L} 4$.

\begin{tabular}{|c|c|c|c|}
\hline \multirow{2}{*}{ Name of fatty acid } & \multirow{2}{*}{$\begin{array}{c}\text { Type of fatty } \\
\text { acid }\end{array}$} & \multicolumn{2}{|c|}{ Percentage of each fatty acid } \\
\hline & & Isolate C5 & Isolate L4 \\
\hline Caproic acid (C6) & Saturated & 1.17 & 0.39 \\
\hline Caprylic acid (C8:0) & Saturated & 2.10 & 0.65 \\
\hline Capric acid (10) & Saturated & 0.27 & 0.08 \\
\hline Undecanoic acid (C11) & Saturated & 0.22 & 0.08 \\
\hline Lauric acid (C12) & Saturated & 0.19 & 0.06 \\
\hline Tridecanoic acid (C13) & Saturated & 0.26 & 0.08 \\
\hline Myristoleic acid (C14) & Unsaturated & 0.63 & 0.23 \\
\hline Myristic acid (C14) & Saturated & 0.38 & 0.26 \\
\hline cis-10-Pentadecenoic acid (C15) & Unsaturated & 0.73 & 0.23 \\
\hline Pentadecanoic cid (C15) & Saturated & 0.31 & 0.12 \\
\hline Palmitoleic acid (C16) & Unsaturated & 1.17 & 0.93 \\
\hline Palmitic acid (C16) & Saturated & 15.59 & 22.18 \\
\hline cis-10-Heptadecenoic acid (C17) & Unsaturated & 1.55 & 0.43 \\
\hline Heptadecanoic acid (C17) & Saturated & 0.73 & 0.27 \\
\hline gama-Linolenic acid (C18) & Unsaturated & 2.62 & 4.52 \\
\hline Linolenic acid (C18) & Unsaturated & 5.93 & 17.94 \\
\hline Oleic acid (C18) & Unsaturated & 44.39 & 38.98 \\
\hline Elaidic acid (C18) & Unsaturated & 2.00 & 2.88 \\
\hline Stearic acid (C18) & Saturated & 2.56 & 2.97 \\
\hline Arachidonic (C20) & Unsaturated & 1.56 & 0 \\
\hline cis-5,8,11,14,17-Eicosapentaenoic acid (C20) & Unsaturated & 1.41 & 0.48 \\
\hline cis-8,11,14-Eicosatrienoic (C20) & Unsaturated & 1.54 & 0.48 \\
\hline cis-11,14-Eicosadienoic acid (C20) & Unsaturated & 0 & 0.46 \\
\hline cis-11-Eicosenoic acid (C20) & Unsaturated & 0 & 0.47 \\
\hline cis-11,14,17-Eicosatrienoic acid (C20) & Unsaturated & 1.42 & 0.45 \\
\hline Arachidic acid (C20) & Saturated & 0.79 & 0.26 \\
\hline Heneicosanoic acid (C21) & Saturated & 1.13 & 0.32 \\
\hline cis-4,7,10,13,16,19-Docosahexaenoic acid (C22) & Unsaturated & 1.54 & 0.52 \\
\hline cis-13,16-Docosadienoic acid(C22) & Unsaturated & 0 & 0 \\
\hline Behenoic acid (C22) & Saturated & 1.89 & 0.63 \\
\hline Tricosanoic acid (C23) & Saturated & 1.36 & 0.55 \\
\hline Nervonic acid (C24) & Unsaturated & 1.63 & 0.50 \\
\hline Lignoceric acid (C24) & Saturated & 2.93 & 1.60 \\
\hline Total fatty acid & & 100 & 100 \\
\hline Total Saturated fatty acids & & 31.88 & 30.50 \\
\hline Total unsaturated fatty acids & & 68.12 & 69.50 \\
\hline
\end{tabular}




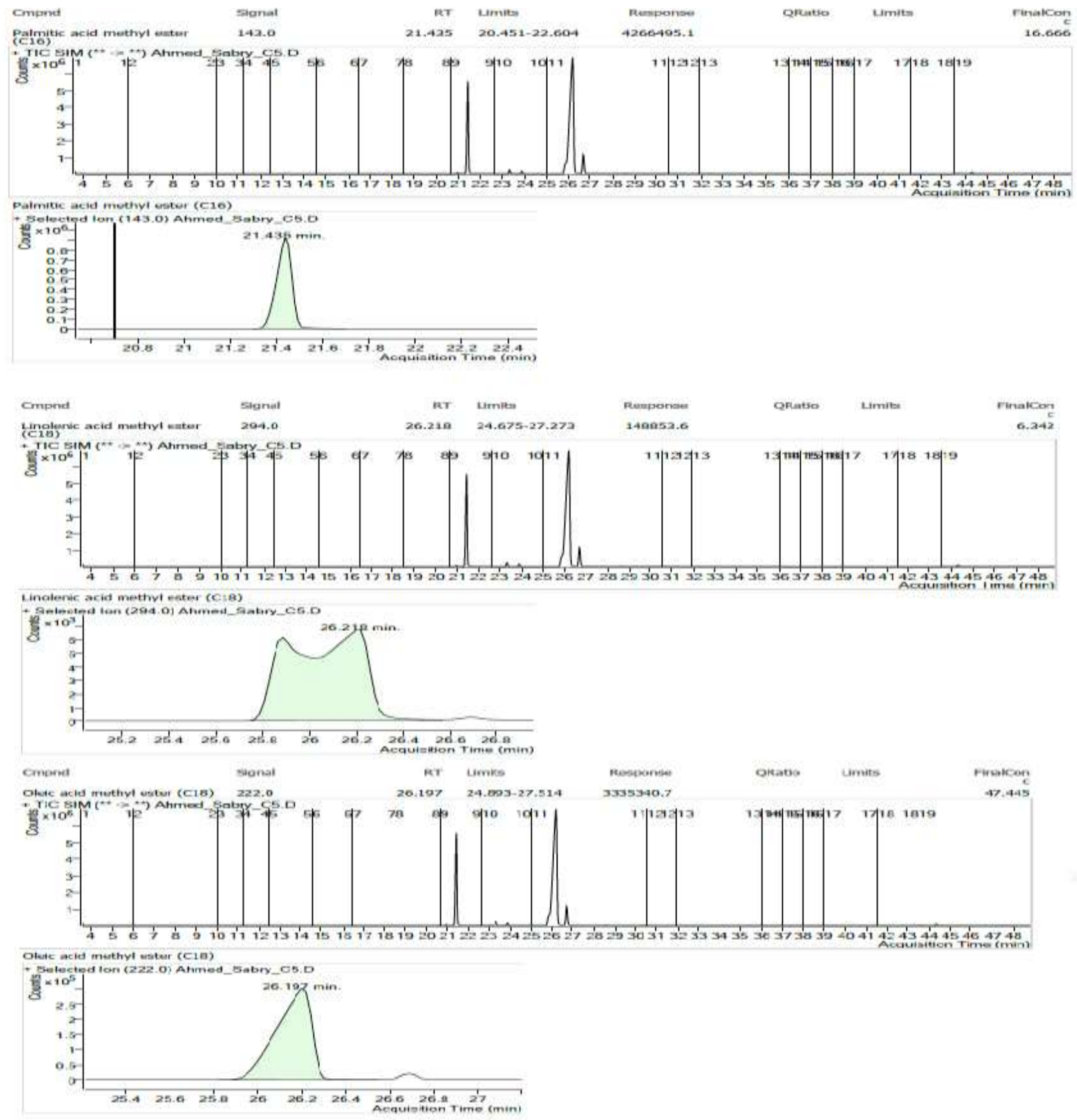

Fig.4. The GC-MS chromatogram showed the main fatty acids composition produced by yeast isolate Candida parapsilosis C5. 


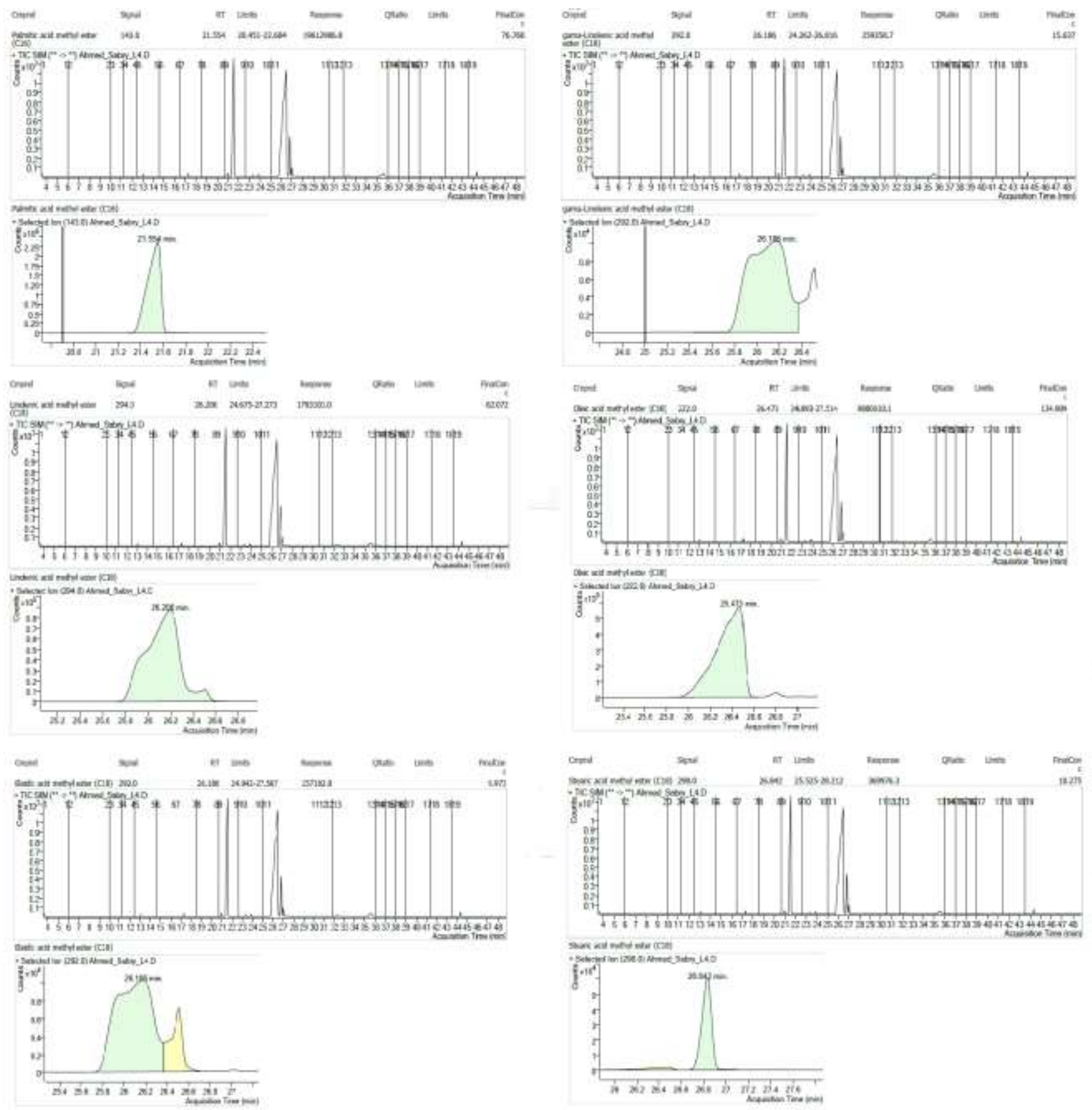

Fig.5. The GC-MS chromatogram showed the main fatty acids composition produced by yeast isolate Cryptococcus albidus L4. 
An appropriate ratio between the composition of unsaturated and saturated fatty acids makes these strains a good candidate to produce polyunsaturated fatty acids with suitable quality as reported by (Knothe, 2005; Liang \& Jiang, 2013) reported that oleaginous yeasts are considered one of the most important tools that preferred to produce fatty acid when compared to plant oils and it is known as oil factories microorganism or single cell oils (SCO). They have numerous advantages such as the scale-up steps of oil production is easier, the shorter life cycle, cost-effective and under control i.e. not affected by climate state or season of cultivation or geographic location like plants.

The comparative study showed that the major fatty acids produced by strains Candida parapsilosis C5 were oleic (C18:1) followed by palmitic acid (C16:0) then linoleic (C18:2) and finally lignoceric (C24), gama-Linolenic acid (C18), Elaidic acid (C18) and stearic (C18:0) acids with 44.39\%, 15.59\%, 5.93\%, 2.93\%, 2.62\%, 2.00\%, and $2.56 \%$, respectively which represent over $76 \%$ of the total fatty acids. On the other hand, the major fatty acids produced by strains Cryptococcus albidus L4 were oleic (C18:1) followed by palmitic acid (C16:0) then linoleic (C18:2) and finally gamma-linolenic acid (C18), stearic acid (C18:0), elaidic acid (C18), and lignoceric acid (C24) with 38.98\%, $22.18 \%, 17.94 \%, 4.52 \%, 2.97 \%, 2.88 \%$, and $1,6 \%$, respectively which represent over $91 \%$ of the total fatty acids. Whereas capric (10), undecanoic (C11), lauric (C12), tridecanoic (C13), pentadecanoic (C15) acids were produced in lesser amounts by both strains (Table 3) (Figs 4, 5).

Also in this study, we observed that the L4 strain not capable to produce arachidonic (C20) fatty acid which may be attributed to the absence of delta-5 desaturase enzyme that responsible for synthesizing arachidonic fatty acid from gama-linolenic acid (C18) (Huang \& Ziboh, 2001).

Arachidonic acid is an essential fatty acid obtained from food such as poultry, meat, fish, seafood, and eggs (Khan, et al., 2017). It's incorporated in phospholipids in the cells' cytosol, adjacent to the endoplasmic reticulum membrane that is studded with the proteins necessary for phospholipid synthesis and their allocation to the diverse biological membranes. Arachidonic acid is vital to the operation of the prostaglandin system. Prostaglandins are part of a class of substances called eicosanoids. Eicosanoids influence numerous metabolic activities including platelet aggregation (blood clotting), inflammation, hemorrhages, vasoconstriction and vasodilation, blood pressure, and immune function (James, 2014; Layne, 2018; Thiriet, 2019). Therefore the presence of ARA in the fatty acids profile of isolate C5 makes this strain a sustainable source for large scale production of ARA.

In contrast, the $\mathrm{C} 5$ strain wasn't capable of producing cis-11, 14-eicosadienoic acid (C20), and cis-11-Eicosenoic acid (C20) fatty acids which may be attributed to the absence of delta-9 elongase enzyme which converts linoleic acid to eicosadienoic acid (C20). The cis-11-eicosenoic acid (C20) is a monounsaturated fatty acid called gondoic acid that is contained in a variety of plant oils and nuts. In particular, eicosadienoic acid represents 
$70 \%$ of the total fatty acids in jojoba oil (Kumar et al., 2020) Jojoba oil is remarkable for its industrial usage, which is in engine lubricating oil, pharmaceutical compounds, and cosmetics also, used as a raw material for medical supplies and a moisturizing component of cosmetic creams as well as it is used as a precursor of erucic acid (C22) in higher plants (Pratt et al., 2002; Padgett, 2015).

Eicosadienoic acid is an omega- 6 fatty acid that is found mainly in small amounts in animal tissues that be able to modulate the metabolism of polyunsaturated fatty acids and alter the responsiveness of macrophages to inflammatory stimulations as well as it can inhibit the binding of leukotriene B4 to pig neutrophil membranes, which may account in part for its anti-inflammatory activities (Schunck et al., 2018; Kimura et al., 2020). Therefore the presence of cis-11, 14-Eicosadienoic acid (C20) and cis-11-Eicosenoic acid (C20) in the fatty acids profile of isolate L5 makes this strain a sustainable source for large scale production of these acids.

The highest content of total unsaturated fatty acid (USFA) was present in strain Cryptococcus albidus L4 $\simeq 70 \%$ followed by strain Candida parapsilosis C5 $\simeq 68 \%$. Whereas the major content of total saturated fatty acids (SFAs) was showed in strain Candida parapsilosis $\mathrm{C} 5$ with $\simeq 32 \%$ followed by strain $\mathrm{L} 4$ with $\simeq 30.5 \%$ of total fatty acids. These results are similar and fully consistent with data reported by (Dalia et al., 2014) and her co-authors they revealed that Candida tropicalis S5 and Pichia kudriavzevii D5 strains produced $30.33 \%$ and $27.55 \%$, of total saturated fatty acids and $67.57 \%$ and $71.43 \%$, of total unsaturated fatty acid, respectively. Also, with data recorded by Barghoth et al. (2018) they isolated two strains of Candida parapsilosis encoded E2 and D1 have the potentially to produce unsaturated fatty acids and saturated fatty acids content $\simeq 70 \%$ and $\simeq 30 \%$, respectively.

In this work, the fatty acid compositional profiles determined for strains Candida parapsilosis C5 and Cryptococcus albidus L4 mainly consisted of oleic acid (C18:1), palmitic acid (C16:0), linolenic acid (C18:2), stearic acid (C18:0), and palmitoleic acid (C16:1) in both oleaginous strains. The content of these unsaturated fatty acids comprised up to $70-91 \%$ of total fatty acid content and increased in presence of a high amount of carbon and a limited amount of nitrogen sources. Also, the fatty acid profiles of these strains are quite similar to oils extracted from different plant sources such as cottonseed, sunflower, rapeseed, and soybean, and these results correspond with those observed by (Li et al., 2007; Amaretti et al., 2010; Kraisintu et al., 2010; Dalia et al., 2014; Vinarta et al., 2016).

Therefore, the results of fatty acids profiles of strains Candida parapsilosis $\mathrm{C} 5$ and Cryptococcus albidus L4, indicated that the microbial lipids produced by these strains are highly rich in a quite fatty acid might be utilized as a promising tool for polyunsaturated fatty acids production similar to that produced from plant oils origins. 
Also, (Kennedy et al., 2010) pointed out that unsaturated linoleic acids are used for obesity treatment by lowering the required energy and increasing the fat mobilization process during the fatty acid oxidation step. Furthermore oleaginous yeasts that have the potential ability to produce dietary fatty acids such as linoleic (essential omega- 6 fatty acid) and palmitoleic in high percent might be used as an alternative tool for biotechnological application for nutritional utilization as previously described by (Sitepu $\boldsymbol{e t}$ al., 2013).

\section{Conclusion}

Results obtained in this work revealed that the marine environment is a promising source for the isolation of oleaginous yeasts. During this work, 20 yeast isolates were obtained from different marine samples. Amongst these two isolates encoded as C5 and L4 were selected as promising alternative sources for the production of polyunsaturated fatty acids (PUFAs) they storage a valuable content of cellular lipid more than $20 \%$ per cell dry weight. These strains were identified as Candida parapsilosis C5 and Cryptococcus albidus L4 based on genetic approach taxonomy. Fatty acid profile of these strain composed of a mixture of fatty acids similar to those present in vegetable oils such as triacylglycerols (TAG), linoleic acid (C18:2), oleic acid (C18:1), stearic acid (C18:0), and palmitic acid (C16:0) which represent over $76 \%$ for isolate C5 and 91\% for isolate L4 of the total fatty acids. An appropriate content of these fatty acids could be used in different applications such as biodiesel production also, Linolenic acid (omega-3) produced by these strains is very important to be applicable in food and pharmacological applications. Further investigations are recommended to improve and increase lipid production through several optimization processes.

\section{REFERENCES}

Abd El Razak A, Ward AC, Glassey J. (2014). Screening of marine bacterial producers of polyunsaturated fatty acids and optimisation of production. Microb Ecol, 67:45464.

Ageitos, J. M., Vallejo, J. A., Veiga-Crespo, P., \& Villa, T. G. (2011). Oily yeasts as oleaginous cell factories. Applied Microbiology and Biotechnology, 90(4), 12191227.

Amaretti, A., Raimondi, S., Leonardi, A., Rossi, M., (2012). Candida Freyschussii: an Oleaginous Yeast Producing Lipids from Glycerol. Chem. Eng. Trans., 27, 139144.

Amaretti, A., Raimondi, S., Sala, M., Roncaglia, L., De Lucia, M., Leonardi, A., Rossi, M., (2010). Single cell oils of the cold-adapted oleaginous yeast Rhodotorula glacialis DBVPG 4785. Microb. Cell Fact. 9, 73. 
Arora, K., D.R. Batish, H.P. Singh and R.K. Kohli (2015). Allelopathic potential of the essential oil of wild marigold (Tagetes minuta L.) against some invasive weeds. Journal of Environmental \& Agricultural Sciences. 3:56-60.

Barghoth, M. G., Zarea, A. A., Desouky, S. E., Abu-Elreesh, G. M., Azab, M. S. (2018). Unsaturated fatty acids production by oleaginous yeast obtained from different marine sources. wjpmr, 4(6), 307-321.

Beopoulos, A., Cescut, J., Haddouche, R., Uribelarrea, J.-L., Molina-Jouve, C., Nicaud, J.- M. (2009). Yarrowia lipolytica as a model for bio-oil production. Prog. Lipid Res. 48, 375-387.

Bligh, E. G. and Dyer, W. J. (1959). A rapid method of total lipid extraction and purification. Canadian Journal of Biochemistry and Physiology, 37(8), 911-917.

Bruder, Stefan, et al. (2018)."Conventional and oleaginous yeasts as platforms for lipid modification and production." Lipid Modification by Enzymes and Engineered Microbes. AOCS Press, 257-292.

Chang, Y. H., Chang, K. S., Lee, C. F., Hsu, C. L., Huang, C. W., \& Jang, H. D. (2015). Microbial lipid production by oleaginous yeast Cryptococcus sp. in the batch cultures using corncob hydrolysate as carbon source. Biomass and Bioenergy, 72, 95-103.

Czabany, T., Athenstaedt, K., Daum, G. (2007). Synthesis, storage and degradation of neutral lipids in yeast. Biochim. Biophys. Acta, 1771, 299-309.

Dalia M. M., Enas A. H. , Fatma H. A., H.K. Abd E. and E.M. R. (2014). Evaluation of Lipid-producing Yeast for Biodiesel Production. Egypt. J. Microbiol. 49, 81- 98.

Daniel, J., Maamar, H., Deb, C., Sirakova, T. D., \& Kolattukudy, P. E. (2011). Mycobacterium tuberculosis uses host triacylglycerol to accumulate lipid droplets and acquires a dormancy-like phenotype in lipid-loaded macrophages. PLoS Pathog, 7(6), e1002093.

Diwan, B., and Gupta, p. (2020)."A Deuteromycete isolate Geotrichum candidum as oleaginous cell factory for medium-chain fatty acid-rich oils." Current Microbiology 77.11: 3738-3749.

El-Fadaly, H.A., El-Ahmady, El-Naggar, N., Marwan, E.M., (2009). Single Cell Oil production by an oleaginous yeast strain in a low cost cultivation medium. Res. $J$. Microbiol., 4, 301-313. 
Enshaeieh, M., Nahvi, I., Madani, M, (2014). Improving microbial oil production with standard and native oleaginous yeasts by using Taguchi design. Int. J. Environ. Sci. Technol., 11, 597-604.

Govender, T., Ramanna, L., Rawat, I., \& Bux, F. (2012). BODIPY staining, an alternative to the Nile Red fluorescence method for the evaluation of intracellular lipids in microalgae. Bioresource Technology, 114, 507-511.

Harwood, John L. (2019). "Algae: critical sources of very long-chain polyunsaturated fatty acids." Biomolecules 9.11: 708.

Huang, Y. S., \& Ziboh, V. A. (Eds.). (2001). Gamma linolenic acid: recent advances in biotechnology and clinical applications.

James, C. H. (2014). The Role of Transient Receptor Potential Vanilloid Member 4 (TRPV4) in Regulating Endothelial Integrity and Vasodilatory Mediator Release: Implications for Vascular and Pulmonary Responses. University of Surrey (United Kingdom).

Kennedy, A., Martinez, K., Schmidt, S., Mandrup, S. et al., (2010). Antiobesity mechanisms of action of conjugated linoleic acid. J. Nutr. Biochem, 21, 171-179.

Khan, S. A., Khan, A., Khan, S. A., Beg, M. A., Ali, A., \& Damanhouri, G. (2017). Comparative study of fatty-acid composition of table eggs from the Jeddah food market and effect of value addition in omega-3 bio-fortified eggs. Saudi journal of biological sciences, 24(4), 929-935.

Kimura, I., Ichimura, A., Ohue-Kitano, R., \& Igarashi, M. (2020). Free fatty acid receptors in health and disease. Physiological reviews, 100(1), 171-210.

Kimura, K., Yamaoka, M., \& Kamisaka, Y. (2004). Rapid estimation of lipids in oleaginous fungi and yeasts using Nile red fluorescence. Journal of microbiological Methods, 56(3), 331-338.

Klymiuk, A. A. (2018). Microbiological insights into ecology and taphonomy of prehistoric wetlands (Doctoral dissertation, University of Kansas).

Knothe, G. (2005). Dependence of biodiesel fuel properties on the structure of fatty acid alkyl esters. Fuel Processing Technology, 86, 1059-1070.

Kosa G, Kohler A, Tafintseva V, Zimmermann B, Forfang K, Afseth NK, Tzimorotas D, Vuoristo KS, Horn SJ, Mounier J. (2017). Microtiter plate cultivation of oleaginous fungi and monitoring of lipogenesis by high-throughput FTIR spectroscopy. Microb Cell Fact.;16:101. 
Kosa, G., Boris Zimmermann, Achim Kohler, Dag Ekeberg, Nils Kristian Afseth, Jerome Mounier, and Volha Shapaval (2018). High-throughput screening of Mucoromycota fungi for production of lowand high-value lipids. Biotechnol Biofuels (2018) 11:66

Kraic, Ján, et al., (2018). "Progress in the genetic engineering of cereals to produce essential polyunsaturated fatty acids." Journal of biotechnology, 284: 115-122.

Kraisintu, P., Yongmanitchai, W., Limtong, S. (2010). Selection and optimization for lipid production of a newsly isolated oleaginous yeast. Rhodosporidium toruloides DMKU3-TK16. Kasetsart J. Nat. Sci., 44, 436-445.

Krieg, N. R., \& Padgett, P. J. (2011). Phenotypic and physiological characterization methods. In Methods in microbiology (Vol. 38, pp. 15-60). Academic Press.

Kumar, R. Praveen, et al., (2019). Refining biomass residues for sustainable energy and bioproducts: technology, advances, life cycle assessment, and economics. Academic Press, 2019.

Kurtzman, C., Fell, J.W., Boekhout, T., (2011). The Yeasts: a Taxonomic Study. Elsevier.

Kumar, P., Lee, J. H., Beyenal, H., \& Lee, J. (2020). Fatty acids as antibiofilm and antivirulence agents. Trends in microbiology.

Layne, K. A. (2018). Anti-inflammatory effects of anti-platelet drugs: implications for atherosclerosis (Doctoral dissertation, King's College London).

Li, Q., du, W., Liu, D. (2008). Perspectives of microbial oils for biodiesel production. Appl. Microbiol. Biotechnol. 80, 749-756.

Li, Y.H., Liu, B., Zhao, Z.B., Bai, F.W., (2007). High-density cultivation of oleaginous yeast Rhodosporidium toruloides Y4 in fed-batch culture. Enzyme Microb. Technol. J., 41, 312-317.

Liang, M.-H., Jiang, J.-G., (2013). Advancing oleaginous microorganisms to produce lipid via metabolic engineering technology. Prog. Lipid Res. 52, 395-408.

Magdouli S, Yan S, Tyagi R, Surampalli R. (2014). Heterotrophic microorganisms: a promising source for biodiesel production. Crit Rev Environ Sci Technol.; 44:41653.

Marika, N., Alissara R., Mallika B., Kongkeitkajorn (2021). Assessing oleaginous yeasts for their potentials on microbial lipid production from sugarcane bagasse and the 
effects of physical changes on lipid production. Bioresource Technology Reports Volume 14, 100650.

Maza, Daniela \& Viñarta, Silvana \& Su, Ying \& Guillamón, José \& Aybar, Manuel. (2020). Growth and lipid production of Rhodotorula glutinis R4, in comparison to other oleaginous yeasts. Journal of Biotechnology, 310; 21-31.

Mbagwu, M. C. (2017). Production, Characterization and Optimal Performance Studies of Glucose Isomerase Byachromobacter Xylosoxidans Mck-4 Isolated from Starch Milling Wastes (Doctoral dissertation).

Meng, X., Yang, J., Xu, X., Zhang, L., Nie, Q., Xian, M. (2009). Biodiesel production from oleaginous microorganisms. Renew. Energy 34, 1-5.

Mohanty, Bimal Prasanna, et al. (2019)."Nutritional composition of food fishes and their importance in providing food and nutritional security." Food chemistry 293: 561570.

Nilsson, Anders K., Carlos Jiménez, and Angela Wulff. (2020). "Nutraceutical Fatty Acid Production in Marine Microalgae and Cyanobacteria." Nutraceutical Fatty Acids from Oleaginous Microalgae: A Human Health Perspective, 23-76.

Ochsenreither K, Glück C, Stressler T, Fischer L, Syldatk C. (2016). Production strategies and applications of microbial single cell oils. Front Microbiol., 7:1539.

Osorio-Gonzalez, C.S., Hegde, K., Ferreira, P., Brar, S.K., Kermanshahipour, A., Soccol, C.R., Avalos-Ramirez, A. (2019). Lipid production in Rhodosporidium toruloides using C-6 and C-5 wood hydrolysate: a comparative study. Biomass Bioenergy 130, 105355.

Pan, L.X., Yang, D.F., Shao, L., Li, W., Chen, G.G. and Liang Z.Q. (2009) Isolation of oleaginous yeast from the soil and studies of their lipid-producing capacities, Food Technology and Biotechnology, 47, 215-220.

Papanikolaou, S., Aggelis, G. (2011). Lipids of oleaginous yeasts. Part I: biochemistry of single cell oil production. Eur. J. Lipid Sci. Technol. 113, 1031-1051.

Park, Y.-K., Nicaud, J.-M., Ledesma-Amaro, R., (2017). The engineering potential of Rhodosporidium toruloides as a workhorse for biotechnological applications. Trends Biotechnol. 36.

Padgett, $\boldsymbol{P}$. (2015). The green beauty rules: The essential guide to toxic-free beauty, green glamour, and glowing skin. Simon and Schuster. 
Pratt, J. H., Henry, E. M. T., Mbeza, H. F., Mlaka, E., \& Satali, L. B. (2002). Malawi agroforestry extension project marketing \& enterprise program, main report. Malawi Agroforestry, 47, 139.

Ratledge, C., Wynn, J.P. (2002). The biochemistry and molecular biology of lipid accumulation in oleaginous microorganisms. Adv. Appl. Microbiol., 51, 1-51.

Ravikumar, K., Dakshayini, J., Girisha, S.T. (2012). Biodiesel production from oleaginous fungi. Int. J. Life Sci., 6, 43-49.

Rubiolo, P., Sgorbini, B., Liberto, E., Cordero, C., \& Bicchi, C. (2010). Essential oils and volatiles: sample preparation and analysis. A review, Flavour and Fragrance Journal, 25(5), 282-290.

Ryan J, Farr H, Visnovsky $S$ et al. (2010). A rapid method for the isolation of eicosapentaenoic acid-producing marine bacteria. J Microbiol Methods, 82:49-53.

Schunck, W. H., Konkel, A., Fischer, R., \& Weylandt, K. H. (2018). Therapeutic potential of omega-3 fatty acid-derived epoxyeicosanoids in cardiovascular and inflammatory diseases. Pharmacology \& therapeutics, 183, 177-204.

Sitepu, I. R., R. Sestric, L. Ignatia et al., (2013). "Manipulation of culture conditions alters lipid content and fatty acid profiles of a wide variety of known and new oleaginous yeast species," Bioresource Technology, vol. 144, pp. 360-369.

Saini, R. K., \& Keum, Y. S. (2018). Omega-3 and omega-6 polyunsaturated fatty acids: Dietary sources, metabolism, and significance-A review. Life sciences, 203, 255267.

Sprague, Matthew, James R. Dick, and Douglas R. Tocher. (2016). "Impact of sustainable feeds on omega-3 long-chain fatty acid levels in farmed Atlantic salmon, 20062015." Scientific reports 6.1: 1-9.

Thiriet, M. (2019). Vasculopathies: Behavioral, Chemical, Environmental, and Genetic Factors (Vol. 8). Springer.

Vadivelan, G., \& Venkateswaran, G. (2014). Production and enhancement of omega-3 fatty acid from Mortierella alpina CFR-GV15: its food and therapeutic application. BioMed Research International, vol. 2014, Article ID 657414, 9 pages.

VanDijken,J.P. , J. Bauer, L. Brambilla, P. Duboc, J.M. Francois, C. Gancedo, M.L. Giu seppin, J.J. Heijnen, M. Hoare, H.C. Lange, et al. (2000). An interlaboratory comparison of physiological and genetic properties of four Saccharomyces cerevisiae strains. Enzyme Microb. Technol., 26 , pp. 706-714 
Visioli, F., \& Poli, A. (2020). Fatty Acids and Cardiovascular Risk. Evidence, Lack of Evidence, and Diligence. Nutrients, 12(12), 3782.

Vinarta, S.C., Angelicola, M.V., Barros, J.M., Fernandez, P.M., Mac Cormak, W., Aybar, M.J., de Figueroa, L.I.C., (2016). Oleaginous yeasts from Antarctica: screening and preliminary approach on lipid accumulation. J. Basic Microbiol. 56, 1360-1368.

Wang, Bo, and Peter Tontonoz. (2019). "Phospholipid remodeling in physiology and disease." Annual review of physiology 81; 165-188.

Xue, S. J., Chi, Z., Zhang, Y., Li, Y. F., Liu, G. L., Jiang, H. \& Chi, Z. M. (2018). Fatty acids from oleaginous yeasts and yeast-like fungi and their potential applications. Critical Reviews in Biotechnology, 38(7), 1049-1060.

Yeung, Yiu T., et al. (2018). "Signaling pathways in inflammation and anti-inflammatory therapies." Current pharmaceutical design 24.14: 1449-1484.

Yuangsaard, N., Yongmanitchai, W., Yamada, M., \& Limtong, S. (2013). Selection and characterization of a newly isolated thermotolerant Pichia kudriavzevii strain for ethanol production at high temperature from cassava starch hydrolysate. Antonie Van Leeuwenhoek, 103(3), 577-588.

Zhu, Z., Zhang, S., Liu, H., Shen, H., Lin, X., Yang, F., Zhou, Y.J., Jin, G., Ye, M., Zou, H., Zhao, Z.K. (2012). A multi-omic map of the lipid-producing yeast Rhodosporidium toruloides. Nat. Commun. 3, 1112. 


\section{عزل وتوصيف الخمائر الزيتية البحرية المنتجة للاحماض الدهنية}

$$
\begin{aligned}
& \text { '*عبدالمعز عبدالنبى زارع , 'سعيد السيد دسوقى , 'جاداله منصور ابو الريش , 'محمد جمال برغوث , 'محمد محمد رشدي } \\
& \text { رشدي } \\
& \text { 'قسم النبات و الميكروبيولوجى - كلية العلوم بنين - جامعة الازهر - مدينة نصر - القاهرة - مصر } \\
& \text { كدينة الابحاث العلمية برج العرب ,الاسكندرية ,مصر }
\end{aligned}
$$

\section{abd-elmoez@azhar.edu.eg : *البريد الاكترونى للباحث الرئيسى}

يوجد اهتمام كبير بالبحث عن مصادر دهنية جديدة مثل الخلايا الميكروبية التي يمكن استخدامها كعامل رئيسي

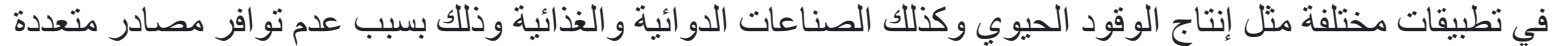

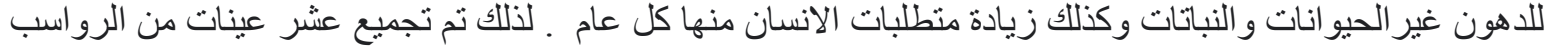

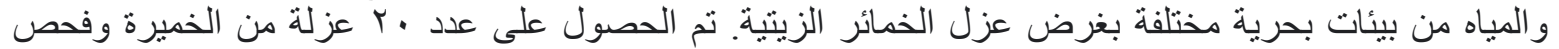

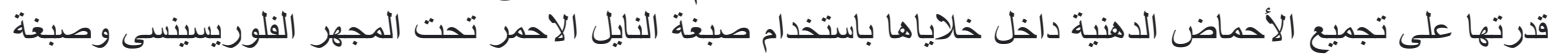

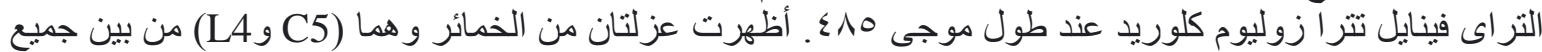

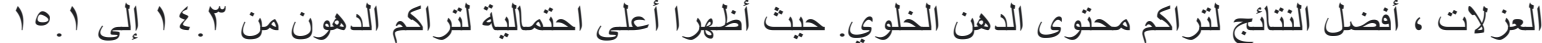

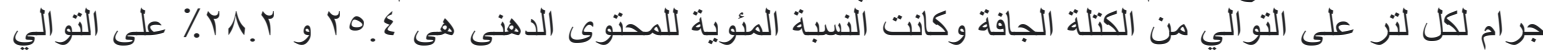

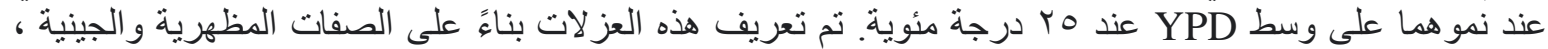

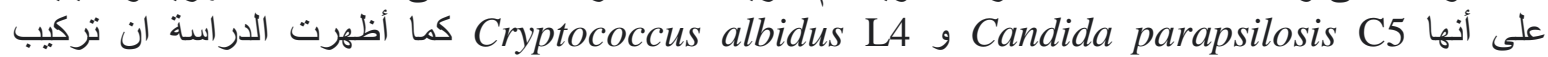

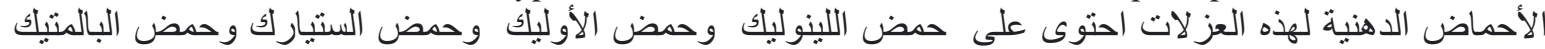

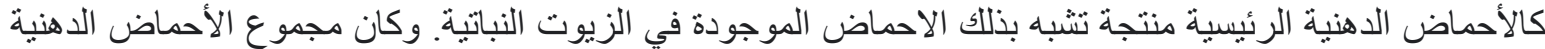

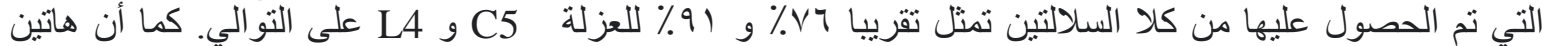

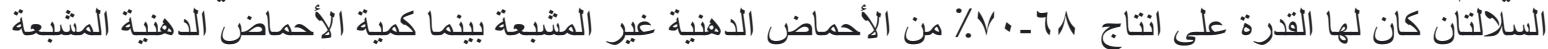

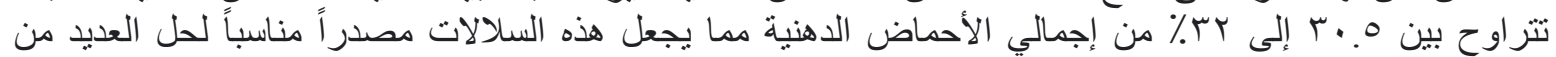

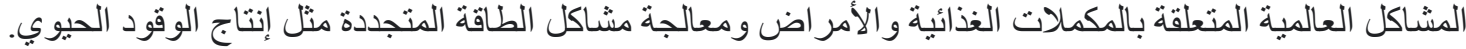

الكلمات المفتاحية : عزل ،البحرية ، الزيتية، الاحماض الدهنية المتعددة غبر المشبعه ، انتاج الدهون ، الفحص ، كانديدا بار ابسيلوسيز ، كرييتوكوكس البيدس 